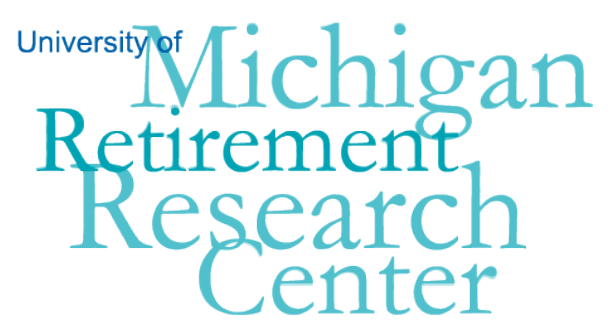

Working Paper

WP 2013-299

\title{
Evaluating Web-based Savings Interventions: A Preliminary Assessment
}

\author{
Wei-Yin Hu, Olivia S. Mitchell, Cynthia Pagliaro, and Stephen P. Utkus
}

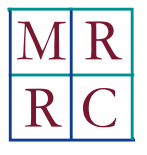

Project \#: UM13-10 



\title{
Evaluating Web-based Savings Interventions: \\ A Preliminary Assessment
}

\author{
Wei-Yin Hu \\ Financial Engines \\ Olivia S. Mitchell \\ The Wharton School of the University of Pennsylvania \\ Cynthia Pagliaro \\ Vanguard Center for Retirement Research \\ Stephen P. Utkus \\ Vanguard Center for Retirement Research
}

October 2013

\author{
Michigan Retirement Research Center \\ University of Michigan \\ P.O. Box 1248 \\ Ann Arbor, MI 48104 \\ www.mrrc.isr.umich.edu \\ (734) 615-0422
}

\section{Acknowledgements}

The research reported herein was performed pursuant to a grant from the U.S. Social Security Administration (SSA) funded as part of the Retirement Research Consortium through the Michigan Retirement Research Center (Grant \# 5 RRC08098401-05-00). The opinions and conclusions expressed are solely those of the author(s) and do not represent the opinions or policy of SSA or any agency of the Federal Government or the Michigan Retirement Research Center.

\section{Regents of the University of Michigan}

Mark J. Bernstein, Ann Arbor; Julia Donovan Darlow, Ann Arbor; Laurence B. Deitch, Bloomfield Hills; Shauna Ryder Diggs, Grosse Pointe; Denise Ilitch, Bingham Farms; Andrea Fischer Newman, Ann Arbor; Andrew C. Richner, Grosse Pointe Park ; Katherine E. White, Ann Arbor; Mary Sue Coleman, ex officio 


\title{
Evaluating Web-based Savings Interventions: \\ A Preliminary Assessment
}

\begin{abstract}
There is reason to believe that technological approaches can help promote voluntary saving in 401(k) retirement accounts. Working with Vanguard, a leading 401(k) plan administrator, we are evaluating the impact of introducing innovations to websites made available to retirement plan participants. The first innovation is a "Boost Your Saving" dial added to several plan homepages immediately after participants log on. The second innovation is a red/yellow/green "Traffic Signal" that can help people evaluate how well they are prepared for retirement. Our goal is to examine contribution and portfolio allocation patterns in the cross-section and also compare pre/post outcomes. The present report provides a preliminary evaluation of the impact on 401(k) plan saving decisions of the web-based savings dial, designed to increase the salience of retirement saving. In what follows, we outline the innovation and some preliminary results. We show that including the savings dial on participants' webpages did boost plan contribution rates. Nevertheless the effect appears to have dissipated after several months, perhaps due to the skewed distribution of participant web logons or to exogenous tax law changes occurring during our evaluation period. We are continuing to evaluate the experiment over time to measure its long-term effects.
\end{abstract}

\section{Citation}

Wei-Yin Hu, Olivia S. Mitchell, Cynthia Pagliaro, and Stephen P. Utkus (2013). "Evaluating Web-based Savings Interventions: A Preliminary Assessment.” Ann Arbor MI: University of Michigan Retirement Research Center (MRRC) Working Paper, WP 2013-299. http://www.mrrc.isr.umich.edu/publications/papers/pdf/wp299.pdf

\section{Authors’ Acknowledgements}

The research reported herein was performed pursuant to a grant from the US Social Security Administration (SSA) to the Michigan Retirement Research Center (MRRC). Additional research support was provided by the Pension Research Council/Boettner center at The Wharton School of the University of Pennsylvania. Opinions and errors are solely those of the authors and not of the institutions with whom the authors are affiliated. (C) 2013, Hu, Mitchell, Pagliaro, and Utkus. All rights reserved 


\section{Evaluating Web-based Savings Interventions: A Preliminary Assessment}

\section{Introduction}

Retirement plan sponsors in various countries including the U.S. have adoption autoenrollment or “opt-out” saving regimes. ${ }^{1}$ In such arrangements, employees are automatically enrolled into workplace-based retirement plans, and plan contribution rates may also be periodically increased. While such efforts have been shown to boost retirement saving rates, only a minority of US workers have been automatically enrolled in retirement plans to date, and automatic contribution escalation programs are relatively uncommon. A recent survey of US employers indicated that only $56 \%$ offered automatic enrollment, and only $26 \%$ offered automatic escalation, with most such features applying prospectively only to new employees (World at Work, 2013). For this reason, many American workers must still make active saving choices when it comes to retirement saving in their defined contribution pension plans. Moreover, absent automatic enrollment into a default investment, most workers continue to make their own portfolio choices, raising concerns about the quality of portfolio diversification among a less sophisticated investor population.

The goal of this project is to explore the efficacy of technological approaches to promote voluntary saving and improve portfolio allocations in 401(k) accounts. In a world where financial decisions are increasingly mediated by technology, whether through the internet or through mobile devices, an emerging question for researchers is how user the design of such mechanisms can influence consequential household financial choices.

\footnotetext{
${ }^{1}$ New Zealand and Australia mandate pension coverage for virtually all employees age 18-65 (Paterson 2013). In the UK, a recent law required all employers to automatically enroll workers into workplace pensions if they are between the ages of 22 and the national retirement age; earn over $£ 9,440$ per year; and work in the UK (Gov.uk, 2013).
} 


\section{Background}

The conventional economics literature on household saving patterns conjectures that rational individuals optimally allocate their time and money over their life cycles, saving when young to support old age consumption. Early research by Modigliani and Brumberg (1954) and Friedman (1957) posited that consumers arranged their optimal saving and decumulation patterns to smooth marginal utility over their lifetimes. This optimization process would be shaped by consumer preferences (e.g., risk aversion and discount rates), the economic environment (e.g., investment returns and liquidity constraints), and social safety net benefits (e.g., the availability and generosity of welfare schemes and Social Security and Medicare benefits). ${ }^{2}$ Such models also generally held that households had the ability to undertake complex economic calculations and implement their plans without difficulty.

More recent research has suggested that such theoretically optimal behavior turns out to be difficult to implement in practice. Around the world, many people lack financial knowledge to design and formulate such plans (Lusardi and Mitchell, 2011). Moreover, they tend to have difficulty turning good intentions into reality. For instance, Bernheim $(1994,1998)$ reported that people often admit to not saving enough, even given incentives to do so. In another study, Beshears et al. (2011) demonstrated that households preferred a savings account with withdrawal restrictions over a fully liquid account, indicating a desire for commitment devices in response to concerns about self-control. In another example, Casari (2009) asked participants in a delayed reward experiment whether they would like to restrict their future choices and found that many would give up money to do so.

\footnotetext{
${ }^{2}$ Recent surveys of the literature on savings appear in Skinner (2007) and Attanasio and Weber (2010); newer advances are offered by Cagetti (2003); Chai, Horneff, Maurer, and Mitchell (2012); DeNardi, French, and Jones (2011); French (2005, 2008); Gourinchas and Parker (2002); Hurst and Aguiar (2005, 2007); and Scholz, Seshadri, and Khitatrakun (2006).
} 
These and related studies in behavioral economics have suggested that assistance or guidance may be required to help households do a better job of saving for retirement (see Mitchell and Utkus, 2004, for a summary). There is clear evidence that auto-enrollment enhances plan participation and boosts retirement contribution patterns (c.f., Madrian and Shea, 2001; Choi et. al., 2003; Thaler and Benartzi, 2004) and that default investment arrangements influence participant portfolio holdings (Mitchell and Utkus, 2012). As a result, over the last decade, some plan sponsors and policymakers have turned to the so-called "choice architecture" approach for retirement savings (Thaler and Sunstein, 2010), where retirement plan sponsors automatically enroll workers into the plans, provide pre-set investment defaults, and sometimes offer autoescalation of contribution rates over time. Other work has focused on the importance of active decisions (Carroll et. al., 2009) in promoting saving. A more recent development has been the use of commitment devices to enhance saving behavior, such as the use of mobile phones to communicate savings "nudges" and exploit peer group effects (Kast, Meier and Pomeranz, 2012).

To date, however, relatively little analysis has been done on how to better inform active employees of the need to save more for retirement. Saving shortfalls are at least in part traceable to poor financial literacy skills (Behrman et al., 2012). That is, around the world people lack a clear understanding of compound interest, risk diversification, and inflation, and these deficits apply to young and older workers alike (Lusardi and Mitchell, 2014). But even when people are better informed and know they need to save more for retirement, they still find it difficult to implement these plans (Hastings and Mitchell, 2011; Hastings, Mitchell, and Chyn, 2011). Accordingly, there has been a growing policy interest in experimental interventions making it easier for retirement plan participants to save more when they decide to do so. 


\section{The "Boost Your Saving” Dial}

At the outset of this project, we proposed to design, implement, and evaluate web-based technologies that could help active members of an employment-based 401(k) plan save more for retirement. In particular, a leading plan administrator has designed and implemented a Boost Your Saving dial in the context of 401(k) retirement plan websites, seeking to evaluate whether this might encourage existing plan participants visiting the site to boost their plan contribution rates immediately. The rationale for this new dial was that participants already had the option of boosting their deferral rates online, but the process could be complicated in practice. Accordingly, the saving dial was designed to test whether increasing the salience and ease of increasing individuals’ plan deferral rates can alter retirement plan contribution behavior. ${ }^{3}$ This effort is distinct from savings mechanisms that propose to increase a participant's plan contribution rate in the future, such as the Save More Tomorrow program.

On December 6, 2012, the Boost Your Saving dial as depicted in Figure 1 was launched. This dial appeared prominently on the "account balance” page seen by existing plan participants when first logging on their 401(k) account. Prior to this, participants had the option of altering their plan contribution rates on the website. Nevertheless, the process involved more steps and was not easily accessible from the home page. Once the dial was introduced, participants could

${ }^{3}$ In related work, we are also exploring a second innovation, namely the introduction of a red/yellow/green "Traffic Signal” that helps participants estimate how well they are prepared for retirement. Provided by the online investment advice provider Financial Engines, the Traffic Signal offers a visual or graphical representation of how well each individual is managing along the road to saving adequacy. Financial Engines develops workers' individualized assessments by running personalized retirement adequacy simulations based on data from certain plans that have authorized the service. Participants may take action in a number of ways, including changing savings rates and portfolio allocations, either on their own or as part of advice programs offered by Financial Engines. Accordingly, this intervention will test whether the graphical presentation of a complex financial metric such as retirement adequacy is effective in changing retirement plan behaviors. As yet the data are not in a form to analyze easily so additional reports will detail these findings as they are made available. 
use it to alter plan contribution rates and, with one click, confirm the change. (Alternatively, they could still alter plan contributions the old way if desired).

Figure 1 here

The dial provides information in a graphical format, rather than offering either textual or numeric data regarding the benefits of increased saving. As such, it was designed to test whether representing the transaction to change savings as a simple graphic icon makes a difference. Moreover, the placement of the dial enhanced the salience of plan contributions, inasmuch as it appeared directly adjacent to the participants' account balance data as soon as they logged on. The Dial also recommended a specific savings increase, either $1 \%, 2 \%$ or $3 \%$, as explained below.

\section{Methods and Data}

The Boost Your Saving dial was first adopted by a set of plan sponsors introducing it to their websites beginning December 6, 2012. It was offered to participants in 1,100 defined contribution retirement plans covering a total potential sample population of 1.5 million participants. The 1.5 million sample includes participants satisfying a series of conditions. First, participants had to be registered to access their accounts via the internet. Second, the dial was offered only to participants currently contributing 1-19\% of pay, inclusive, to their retirement plans. In other words, it excluded workers eligible but not participating in the plan, as well as those contributing $20 \%$ or more of pay. Third, the intervention was offered only to participants contributing from one type (or “source”) of money - namely, either pre-tax contributions or Roth contributions, but not both. Fourth, to see the dial, participants had to log on to their accounts during our evaluation period, November 30, 2012 - May 31, 2013. And fifth, when participants 
did make a change, either increasing or decreasing plan contributions, the dial was removed from their account pages for any subsequent logons.

The dial was labeled with the phrase "Boost Your Savings.” It showed participants their current plan contribution rates and recommended that they boost their contributions by one, two or three percentage points from that base. Participants seeing the dial were randomly assigned to a recommended contribution size increment, based on which minute of an hour they had logged onto the account. For example, someone logging on five minutes after the hour received one of the percentage change offers, someone logging in six minutes after the hour received another, and so on.

Because the Boost Your Saving dial was implemented by the recordkeeper, we were unable to randomly assign plan participants to treatment and control groups during the evaluation period. Instead, we adopt a pre/post treatment comparison as a second-best empirical strategy. That is, we compare changes in plan savings behavior when the dial was offered, with those for a prior period when it was not offered. One candidate for the control period was the six months prior to the launch of the experiment. Another candidate control period was the same six months a year previous, namely November 30, 2011-May 31, 2012. We chose the latter over the former due to the seasonality of plan contribution changes observed in the recordkeeping data. In effect, our control group represents participants who would have seen the savings dial had it been available a year earlier.

\section{Empirical Approach}

To date we have gathered two types of data. The first we refer to as the "aggregate" dataset. It covers daily logon and contribution rate changes over both the treatment period (for 
participants eligible to see the dial), and the control period (for participants who would have seen the dial had it been shown a year prior). This dataset aggregates all changes made to plan contribution rates via the web. Thus, during the treatment period, it includes individuals making changes with the Boost Your Saving dial as well as those using the traditional transaction mechanism available on the website.

The second dataset, referred to here as the "savings dial" dataset, indicates who actually used the dial (drawn from a live website feed), as well as whether the participant logging on saw the one, two or three percentage point increase version. For this second dataset, we also have information on daily changes in plan contribution rates. ${ }^{4}$

Because the datasets were received at the end of August 2013, and the datasets required some time to clean, this report provides preliminary summary statistics on our results to date. Our future research will combine these data with other information on participants including age, sex, income, job tenure, and 401(k) plan account characteristics. The goal will be to further refine our analysis and empirical modeling. We anticipate updating the findings in the near future.

\section{Preliminary Results}

To date we have produced summary statistics on savings rate changes over time using the aggregate dataset, comparing patterns to participants seeing the dial to those from a year earlier when the dial was not available. Table 1 provides summary statistics for the control and treatment periods. During the control period, participants seeking to change plan contributions

\footnotetext{
${ }^{4}$ Because of a technical problem in data-gathering, actual savings dial usage data was missing for 23 days of the November 30, 2012- May 31, 2013 evaluation period. We omit that period from the analysis below.
} 
had to use the traditional transaction approach. During the treatment period, they could have changed contributions using the Boost Your Saving dial or followed the traditional transaction. Results show that some 4-5 million participants logged on monthly during both periods. In the prior period, some $0.42 \%$ of those who logged on boosted their saving rates; during the treatment period, this rose slightly to $0.49 \%$, a relative increase of $17 \%$ before controlling for other differences between the control and treatment groups. The average percentage increase in saving rates was $4.32 \%$ during the control period, and $4.28 \%$ during the treatment period, a relative decline of only $1 \%$, again before controlling for other influences. In the both periods, only about $0.2 \%$ of those who logged on reduced their contribution rates, and the average percentage decrease among these few individuals was a negative 4.1-4.2 percent.

\section{Table 1 here}

Figure 2 provides a graphical depiction of these patterns (data begin in October rather than November as in Table 1). Panel A focuses on increases in contribution rates while Panel B illustrates the difference between the treatment and year-earlier control periods. Interestingly, the pattern of saving increases started after the introduction of the Boost Your Saving dial, and the treatment effect was largest during this initial phase. The boost in saving rates continued for several months, and then it dissipated. We attribute this pattern partly to the fact that web usage among plan participants is highly skewed, with a small fraction of participants logging on frequently (see Figure 3). After this initial exposure, it appears that the effect of the savings dial declined.

Figures 2 and 3 here

We can also detect some slight differences in contributions rate decreases. Table 1 and Figure 4 compare year over year plan contribution rate declines and the summary difference in 
treatment versus control groups. Results suggest that immediately after the Boost Your Saving dial was introduced, some participants actually decreased their contribution rates, especially in January 2013; on average, however, the fraction of decreasers did not change from the same period in the year before.

Figure 4 here

Besides the Savings Dial, there is another alternative explanation for the change we observe in behavior, namely tax changes that occurred in January of 2013. In that month, marginal tax rates rose on upper-income households, and the $2 \%$ Social Security payroll tax suspension ended for all workers. One plausible explanation for the increase in tax-deferred contributions was an effort by high-income households to increase tax-deductible contributions in a higher-rate environment. Similarly, the notable spike among participants reducing their contributions in January 2013 may be a result of certain households reacting to the impact of higher Social Security taxes on take-home pay (or the effect of other benefits changes such as higher health care premiums in the new calendar year). At the same time, the rate of decreasing savings did not change over longer periods between control and treatment group, suggesting these are only small timing differences.

Moreover, it remains to be seen whether the savings dial effect will persist as new participants register on and view the website. Since new hires are relatively fewer in number compared to the existing participants, evaluating a new hire impact will require a longer evaluation period. Future work will seek to disentangle the effects of these various factors by drawing data from later periods.

Table 2 provides summary characteristics of the savings dial sample. In total, almost half a million participants saw the savings dial when they logged into their accounts. Of these, $9 \%$ 
actually used the dial to increase their savings. On average, participants using the Boost Your Saving dial increased their savings 2.1 percentage points, from $7 \%$ to $9.1 \%$. Almost all participants used the dial to increase their saving rate, rather than to decrease it.

Table 2 here

Using the "saving dial” sample, Figure 5 summarizes results on the impact of the default savings increase displayed by the dial. Panel A demonstrates that participants were marginally more likely to use the dial when they were shown a $1 \%$ increase, but slightly less likely to use the dial when they were shown a $3 \%$ increase. Thus $31 \%$ of treated participants saw a recommended three percentage point increase, but they accounted for only $27 \%$ of participants actually increasing their plan contribution rate. Panel B indicates that among participants increasing their contribution rates, just under two-thirds of participants, or $63 \%$, used the recommended increase. Of the remaining $37 \%$ who opted to select their own deferral rate change, those randomly shown the $1 \%$ option boosted their savings on average $1.28 \%$; those shown the $2 \%$ option increased their saving rate an average of $0.73 \%$; and those shown the $3 \%$ option ended up making no essentially no change (-0.07\%).

Figure 5 here

\section{Discussion}

When the Boost Your Saving dial was introduced to plan participants, there was a noticeable jump in those increasing plan contribution rates, especially in the first few months of the experiment. The rate of those decreasing contributions did not change over our six-month treatment period, though there was a noticeable increase in savings reductions in January 2013 that remains to be understood. 
Several considerations are worth noting. One is that we have determined that a large fraction of participants who boosted their saving rates online, some $40 \%$, never saw the dial even though they were eligible. Perhaps because they were impatient, they clicked past the dial before it had time to load on their webpages. Accordingly, we conjecture that the fraction of participants which actually used the dial to change contribution rates is higher.

Another point to note is that the effect of the dial appears to have dissipated after several months. One possible explanation for the dissipating effect is the skewed distribution of participant logon behavior, where the same users tend to long on frequently. Once someone had changed his saving rate, he would no longer see the dial. Consequently the fraction of those logging on and seeing the dial declined with time. As well, regular users of the website, having seen the dial once or twice, but having decided not to make a change, might tend to overlook it with repeated exposure.

Another possible explanation is the sizeable tax law changes that occurred in the early part of January 2013. These changes may have motivated participants to take action to adjust their saving rates in response to these tax changes, either increasing or decreasing plan contributions, and it may explain why further adjustments dampened after the first several months. Additional analysis of the data over time may help disentangle these effects.

It is also important to recognize that our experiment targeted those who were already contributing to an employer retirement program, and who were web-registered to access their accounts online. Moreover, we track only those who accessed and saw the savings dial during the evaluation period. In other words, our findings in the dial experiment do not speak to the experiences of non-savers or those lacking internet access. 


\section{Conclusions and Future Work}

Consistent with expectations, contribution rates rose for those seeing the Boost Your Saving dial compared to the control period. Also compared to a year earlier, the fraction of participants increasing plan contributions upon logon rose by a relative $17 \%$, although from a low base (just under less that $1 / 2$ of $1 \%$ of those logging on daily). Some $9 \%$ used the Boost Your Saving dial, increasing their contribution rates by an average of 2 percentage points. There was no change in the fraction of participants decreasing their contributions.

These findings are relevant to efforts to evaluate programmatic interventions to improve financial literacy and savings, particularly those that address the increasing role of technologybased household financial decisions. Employees and their families are increasingly using electronic media to obtain financial information and conduct financial transactions. Understanding how interventions in the electronic world can alter household saving behavior will continue to deserve research and policy attention. Future work will incorporate additional statistical controls so as to more cleanly extract the impact of the web-based innovation. We also will extend our analysis to longer time periods and additional innovative technological interventions. 


\section{References}

Attanasio, Orazio and Guglielmo Weber. (2010). Consumption and Saving: Models of Intertemporal Allocation and Their Implications for Public Policy. Journal of Economic Literature 48: 693-751.

Behrman, Jere, Olivia S. Mitchell, Cindy Soo, and David Bravo. (2012). Financial Literacy, Schooling, and Wealth Accumulation. American Economic Review. 102(3): 300-304.

Bernheim, Douglas. (1995). Do Households Appreciate their Financial Vulnerabilities? An Analysis of Actions, Perceptions, and Public Policy. In Tax Policy and Economic Growth. Washington, DC: American Council for Capital Formation: 1-30.

Bernheim, Douglas. (1998). Financial Illiteracy, Education, and Retirement Saving. In Living with Defined Contribution Pensions. Eds, O.S. Mitchell and S. Schieber. Philadelphia: University of Pennsylvania Press: 38-68.

Beshears, John, James Choi, David Laibson, Brigitte Madrian, and Jung Sakong. (2011). Self Control and Liquidity: How to Design a Commitment Contract. RAND Working Paper Series WR- 895-SSA.

Cagetti, Marco. (2003). Wealth Accumulation over the Life Cycle and Precautionary Savings. Journal of Business and Economic Statistics 21(3): 339-353.

Carroll, Gabriel D., James Choi, David Laibson, Brigitte C. Madrian and Andrew Metric (2009). “Optimal Defaults and Active Decisions.” Quarterly Journal of Economics. 124(4). November, 1639-1674.

Casari, Marco. (2009). Pre-commitment and Flexibility in a Time Decision Experiment. Journal of Risk and Uncertainty. April 38(2): 117-141 
Chai, Jingjing, Wolfram Horneff, Raimond Maurer, and Olivia S. Mitchell. (2012). Optimal Portfolio Choice over the Life Cycle with Flexible Work, Endogenous Retirement, and Lifetime Payouts. Review of Finance 15(4): 875-907.

Choi, James, David Laibson, Brigitte C. Madrian and Andrew Metrick (2004). "Optimal Defaults.” American Economic Review Papers and Proceedings. 93. 180-185.

DeNardi, Mariacristina, Eric French and John Bailey Jones. (2011). Why Do the Elderly Save? The Role of Medical Expenses. Journal of Political Economy 118(1): 39-75.

French, Eric. (2005). The Effects of Health, Wealth, and Wages on Labor Supply and Retirement Behavior. Review of Economic Studies 72(2): 395-427.

French, Kenneth. (2008). The Cost of Active Investing. Journal of Finance 63: 1537-1573.

Friedman, Milton. (1957). A Theory of the Consumption Function. Princeton: Princeton University Press.

Gourinchas, Pierre-Olivier and Jonathan Parker. (2002). Consumption over the Life Cycle. Econometrica 70 (1): 47-89.

Gov.UK (2013). Workplace Pensions. https://www.gov.uk/workplace-pensions/aboutworkplace-pensions

Hastings, Justine, Olivia S. Mitchell, and Eric Chyn. (2011). Fees, Framing, and Financial Literacy in the Choice of Pension Managers. In Financial Literacy: Implications for Retirement Security and the Financial Marketplace. Eds. O. S. Mitchell and A. Lusardi. Oxford: Oxford University Press: 101-115.

Hastings, Justine and Olivia S. Mitchell. (2011). “How Financial Literacy and Impatience Shape Retirement Wealth and Investment Behaviors.” NBER Working Paper No. 16740. 
Hurst, Eric and Mark Aguiar. 2005. Consumption vs Expenditure. Journal of Political Economy. 113(5): 919-948.

Hurst, Eric and Mark Aguiar. 2007. Measuring Trends in Leisure: The Allocation of Time Over Five Decades. Quarterly Journal of Economics 122(3): 969-1006.

Kast, Felipe, Stephan Meier and Dian Pomeranz. (2012). “Under-Savers Anonymous: Evidence on Self-Help Groups and Peer Pressure as a Savings Commitment Device.” Harvard Business School Working Paper, No. 12-060, October 2012.

Lusardi, Annamaria and Olivia S. Mitchell. (2014). "The Economic Importance of Financial Literacy: Theory and Evidence.” Journal of Economic Literature. Forthcoming March. (NBER WP 18952).

Lusardi, Annamaria and Olivia S. Mitchell. (2011). Financial Literacy around the World: An Overview. Journal of Pension Economics and Finance 10(4): 497-508.

Madrian, Brigitte, and Dennis Shea. (2001). "The Power of Suggestion: Inertia in 401(k) Participation and Savings Behavior.” Quarterly Journal of Economics 116, pp. 11491187.

Mitchell, Olivia S. and Annamaria Lusardi. (eds.) (2011). Financial Literacy: Implications for Retirement Security and the Financial Marketplace. Oxford University Press.

Mitchell, Olivia S. and Stephen Utkus. (2004). Lessons from Behavioral Finance for Retirement Plan Design. In O.S. Mitchell and S. Utkus (eds) Pension Design and Structure: New Lessons from Behavioral Finance. Oxford University Press.

Mitchell, Olivia S. and Stephen Utkus. (2012). Target-Date Funds in 401(k) Retirement Plans. NBER Working Paper No. 17911. 
Mitchell, Olivia S. and Stephen Utkus. (2004). "Lessons from Behavioral Finance for Retirement Plan Design.” In. Pension Design and Structure: New Lessons from Behavioral Finance. Eds. O.S. Mitchell and S.P. Utkus. Oxford, UK: Oxford University Press.

Modigliani, Franco, and Richard Brumberg. (1954). Utility Analysis and the Consumption Function: An Interpretation of Cross-section Data. In Post-Keynesian Economics. Ed. K. Kurihara. New Brunswick, NJ: Rutgers University Press: 388-436.

Paterson, Jennifer. (2013). Auto-enrollment Tips from Australia and New Zealand. Employee Benefits. 28 February. http://www.employeebenefits.co.uk/benefits/pensions/autoenrolment-tips-from-australia-and-new-zealand/101150.article.

Saez, Emanuel. (2009). Details Matter: The Impact of Presentation and information on the Takeup of Financial Incentives for Retirement Savings, American Economic Journal: Economic Policy 1(1): 204-228.

Scholz, John Karl, Ananth Seshadri, and Surachai Khitatrakun. (2006). Are Americans Saving “Optimally” For Retirement? Journal of Political Economy 114: 607-643.

Skinner, Jonathan. (2007). Are You Sure You're Saving Enough for Retirement? Journal of Economic Perspectives. Summer: 59-80.

Thaler, Richard and Shlomo Benartzi. (2004). "Save More Tomorrow: Using Behavioral Economics to Increase Employee Saving.” Journal of Political Economy 112, pp. S164S187.

Thaler, Richard and and Cass Sunstein. (2010). Nudge: Improving Decisions about Health, Wealth, and Happiness. New Haven: Yale University Press.

WorldatWork and the American Benefits Institute. (2013). "Trends in 401(k) Plans and Retirement Rewards.” March. http://www.worldatwork.org/waw/adimLink?id=71489 
Table 1. Aggregate Sample Characteristics

A. Control Period (November 30, 2011 - May 31, 2012)

\begin{tabular}{rrrrrrrr} 
& N Logons & N Increasers & $\%$ Incr & N Decreasers & $\%$ Decr & Av. increase \% & Av. decrease \% \\
\cline { 2 - 7 } Dec 2011 & $4,107,699$ & 14,835 & $0.36 \%$ & 8,240 & $0.20 \%$ & $5.60 \%$ & $-4.37 \%$ \\
Jan 2012 & $5,003,790$ & 23,172 & $0.46 \%$ & 9,978 & $0.20 \%$ & $4.01 \%$ & $-4.11 \%$ \\
Feb 2012 & $4,568,926$ & 20,250 & $0.44 \%$ & 9,496 & $0.21 \%$ & $4.19 \%$ & $-4.41 \%$ \\
Mar 2012 & $4,467,611$ & 20,737 & $0.46 \%$ & 8,038 & $0.18 \%$ & $3.95 \%$ & $-4.03 \%$ \\
Apr 2012 & $4,234,064$ & 19,416 & $0.46 \%$ & 7,738 & $0.18 \%$ & $3.98 \%$ & $-4.03 \%$ \\
May 2012 & $3,980,776$ & 13,014 & $0.33 \%$ & 7,955 & $0.20 \%$ & $4.17 \%$ & $-4.15 \%$ \\
\hline $\begin{array}{c}\text { Average over } \\
\text { period }\end{array}$ & & & $\mathbf{0 . 4 2 \%}$ & & $\mathbf{0 . 2 0 \%}$ & $\mathbf{4 . 3 2 \%}$ & $\mathbf{- 4 . 1 8 \%}$
\end{tabular}

B. Treatment Period (November 30, 2012 - May 31, 2013)

\begin{tabular}{rrrrrrrr} 
& N Logons & N Increasers & $\%$ Incr & N Decreasers & $\%$ Decr & Av. increase \% & Av. decrease \% \\
\cline { 2 - 7 } Dec 2012 & $4,386,859$ & 23150 & $0.53 \%$ & 7483 & $0.17 \%$ & $7.15 \%$ & $-4.34 \%$ \\
Jan 2013 & $5,721,086$ & 34103 & $0.60 \%$ & 14214 & $0.25 \%$ & $3.71 \%$ & $-3.68 \%$ \\
Feb 2013 & $4,443,031$ & 21696 & $0.49 \%$ & 10246 & $0.23 \%$ & $3.87 \%$ & $-4.30 \%$ \\
Mar 2013 & $5,554,553$ & 27431 & $0.49 \%$ & 10574 & $0.19 \%$ & $3.62 \%$ & $-4.00 \%$ \\
Apr 2013 & $5,356,976$ & 25876 & $0.48 \%$ & 9581 & $0.18 \%$ & $3.66 \%$ & $-4.05 \%$ \\
May 2013 & $5,518,997$ & 19618 & $0.36 \%$ & 9022 & $0.16 \%$ & $3.64 \%$ & $-4.20 \%$ \\
\hline $\begin{array}{c}\text { Average over } \\
\text { period }\end{array}$ & & $\mathbf{0 . 4 9 \%}$ & & $\mathbf{0 . 2 0 \%}$ & $\mathbf{4 . 2 8 \%}$ & $-\mathbf{4 . 1 0 \%}$
\end{tabular}

Source: Authors’ tabulations. 
Table 2. Savings Dial Sample Characteristics. Treatment period (November 30, 2012 - May 31, 2013)

A. Summary of Dial Usage

\begin{tabular}{ccccc} 
& $\begin{array}{c}\text { N unique } \\
\text { participants } \\
\text { who saw the } \\
\text { dial }\end{array}$ & $\begin{array}{c}\text { N unique } \\
\text { participants } \\
\text { who used the } \\
\text { dial }\end{array}$ & $\begin{array}{c}\text { \% using } \\
\text { dial }\end{array}$ & $\begin{array}{c}\% \\
\text { increasing } \\
\text { savings }\end{array}$ \\
\cline { 2 - 5 } Dec 2012 & 187,216 & 6,201 & $3 \%$ & $99.8 \%$ \\
Jan 2013 & 152,030 & 8,946 & $6 \%$ & $99.8 \%$ \\
Feb 2013 & $32983^{*}$ & 6,674 & $*$ & $99.9 \%$ \\
Mar 2013 & $10897^{*}$ & 7,353 & $*$ & $100.0 \%$ \\
Apr 2013 & 88,220 & 7,121 & $8 \%$ & $99.9 \%$ \\
May 2013 & 52,755 & 5,285 & $10 \%$ & $100.0 \%$ \\
\cline { 2 - 5 } & 480,221 & 41,580 & $9 \%$ &
\end{tabular}

* 'Saw the Dial' data missing for 19 days in February 2013 and 4 days in March 2013.

B. Summary of Participant Changes

Average contribution

before change

$7.0 \%$

Average contribution

after change

$9.1 \%$

Source: Authors' tabulations 
Figure 1. “Boost Your Saving” Dial

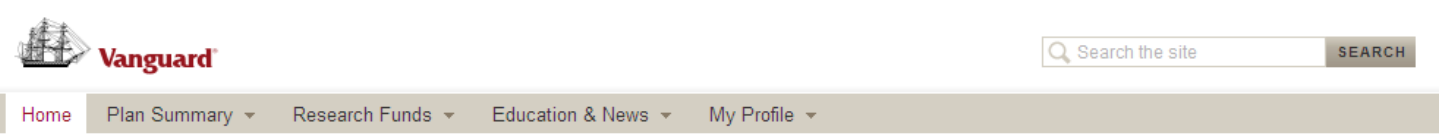

Welcome, Ibts Refer to meas...

E-mali: bitsdemopart@vanguard.com Edit Last logon: Tuesday, May 14, 2013 8:16 AM EDT

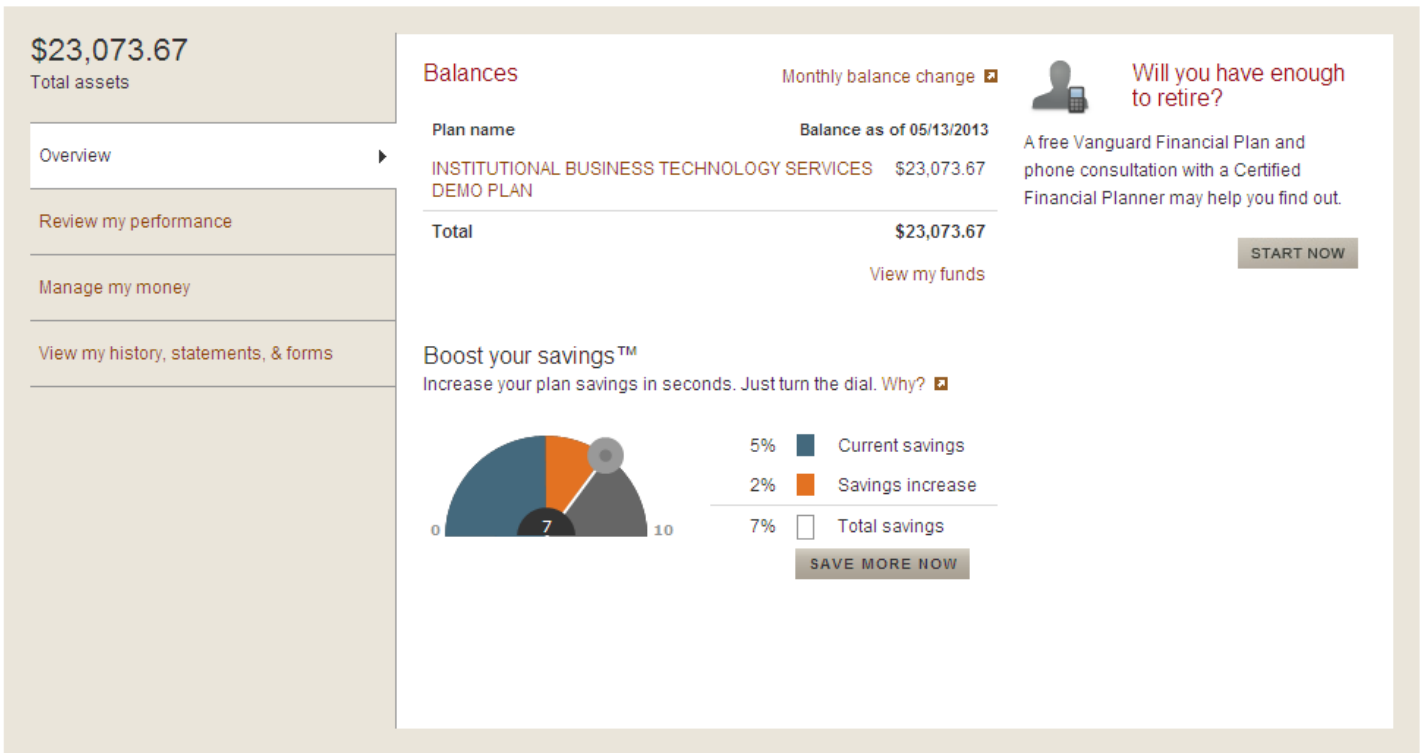




\section{Figure 2. Daily Saving Rate Increases}

A. Year-over-year comparison: Percentage of plan contribution rate increases (October-May)

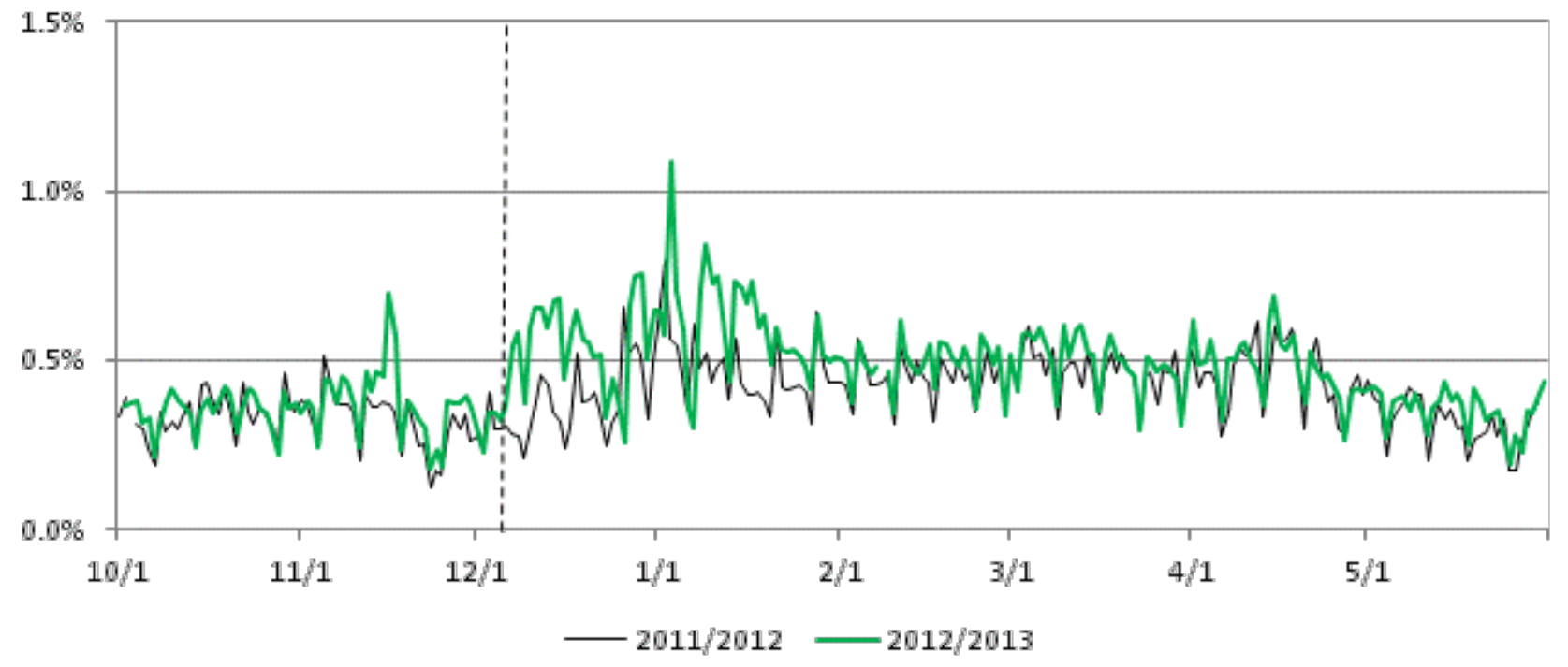

B. Difference in saving rates: Treatment versus Control groups

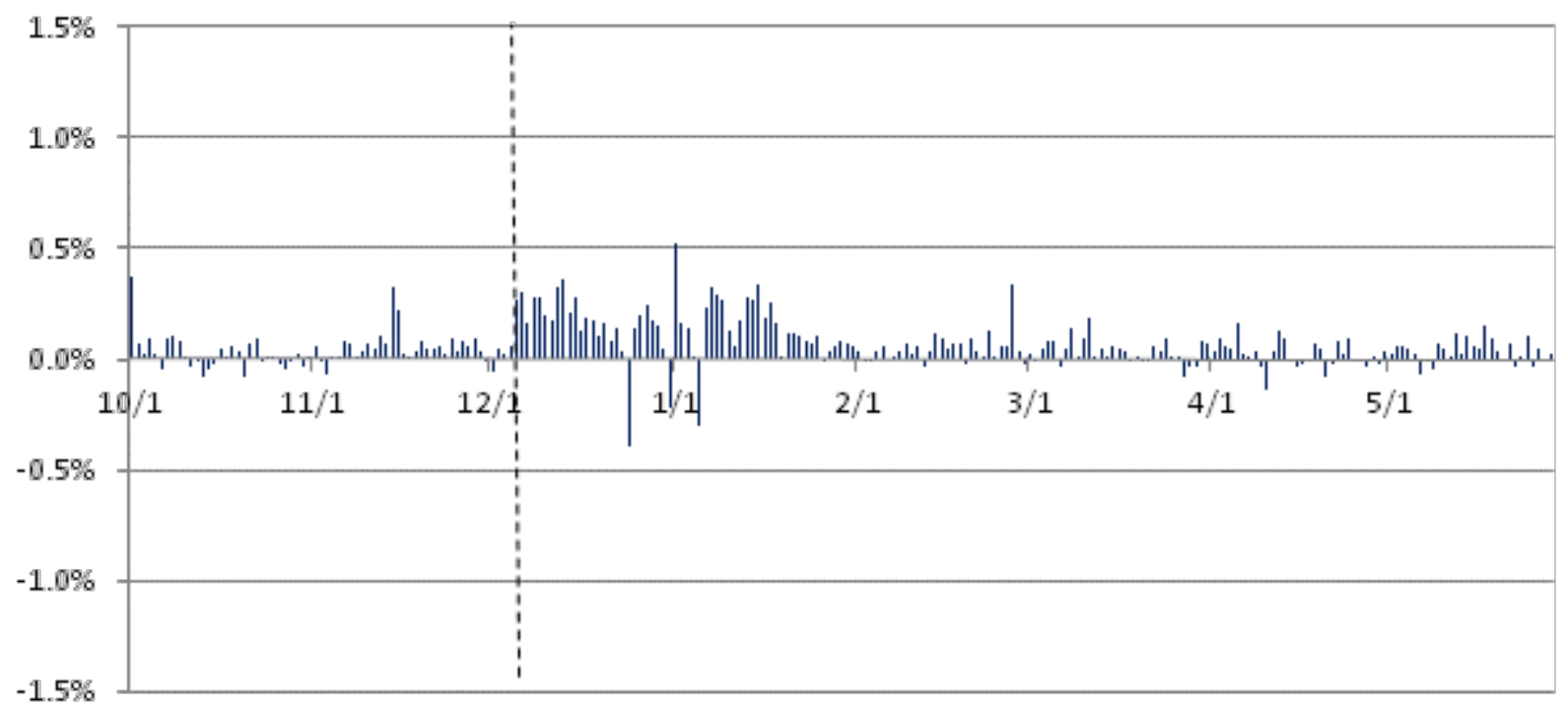

Source: Authors’ tabulations. 
Figure 3. Distribution of Unique Logons. Number of unique participant logons: December 6, 2012May 31, 2013.

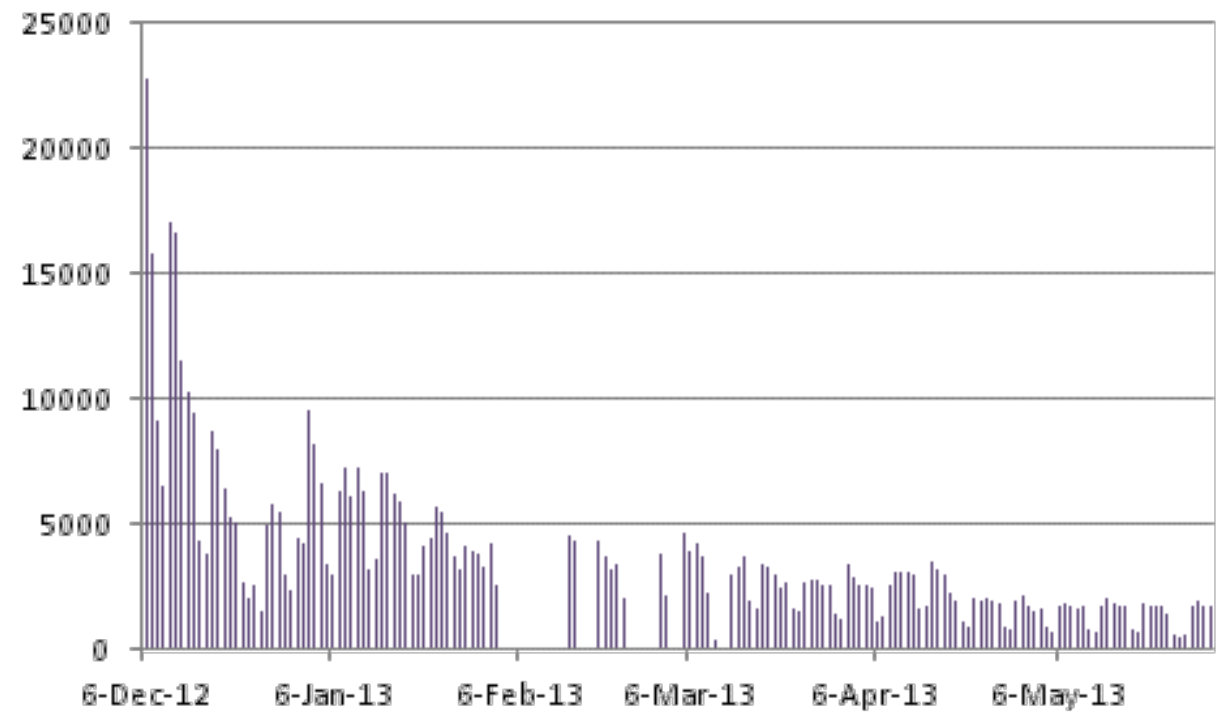

Source: Authors’ tabulations. 
Figure 4. Daily Saving Rate Decreases

A. Year-over-year comparison: Percentage of plan contribution rate decreases (October-May)

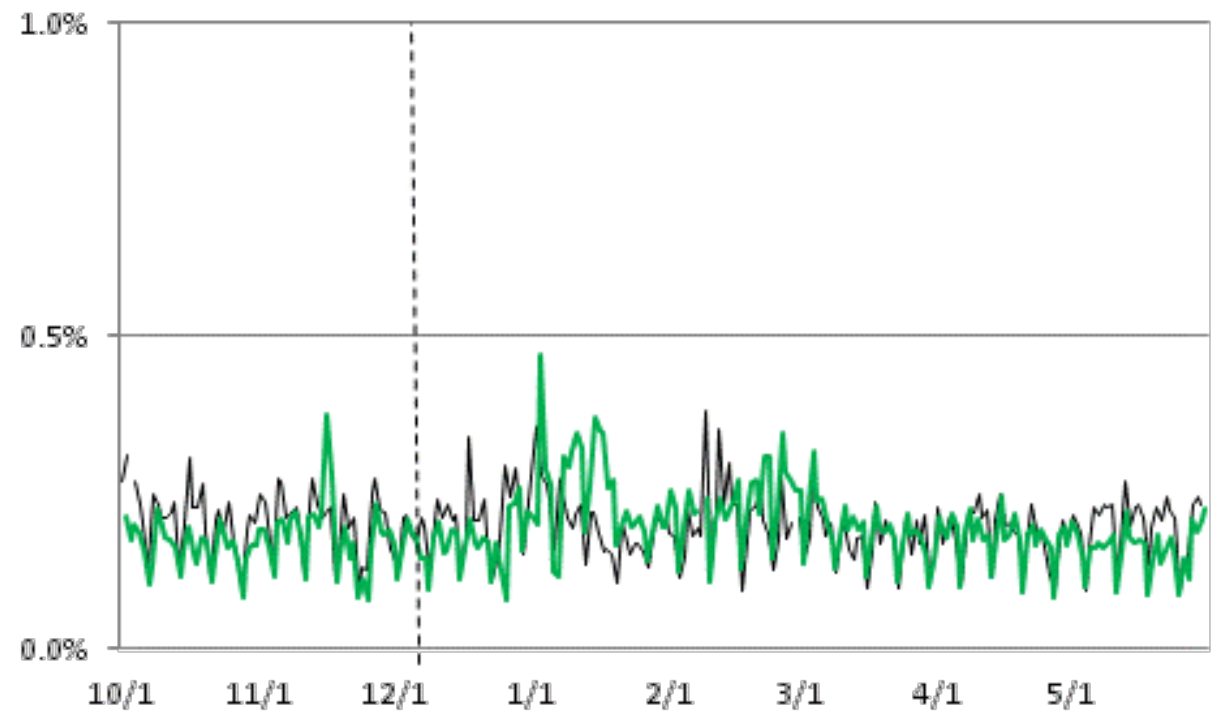

B. Difference in treatment versus control groups

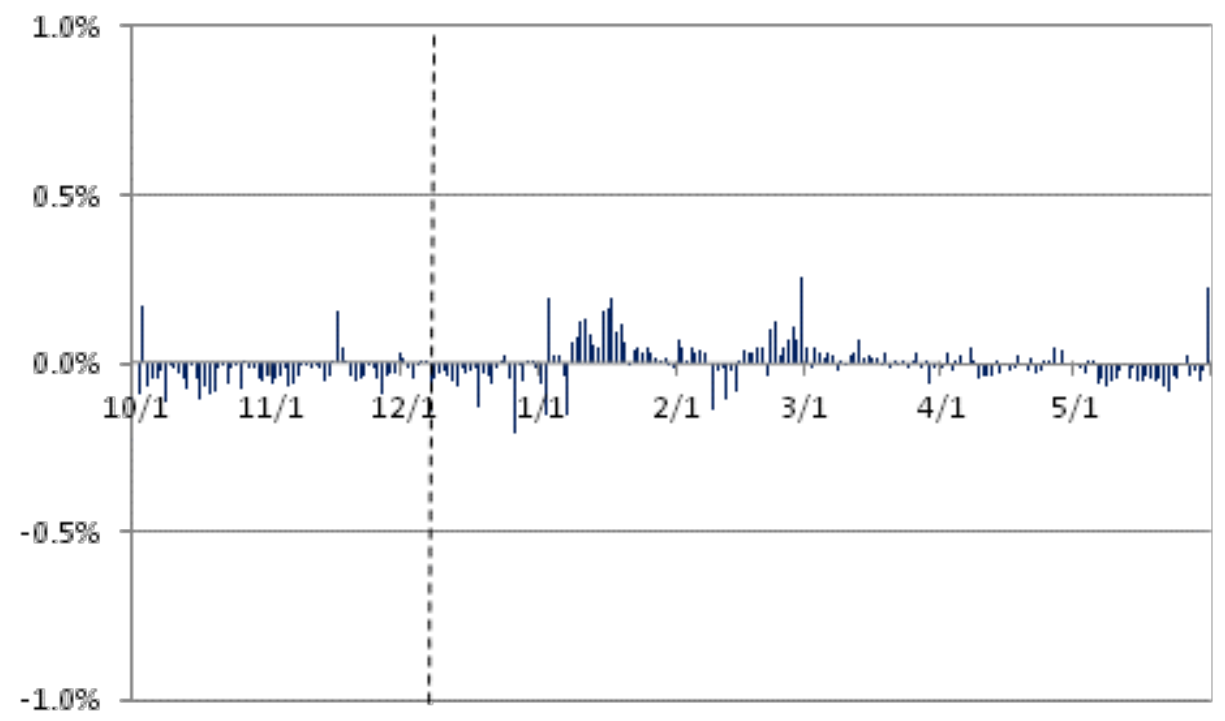

Source: Authors’ tabulations. 
Figure 5. Impact of Savings Dial Default Settings

A. Distribution of default increases displayed to participants who saw the dial compared to those that used the dial

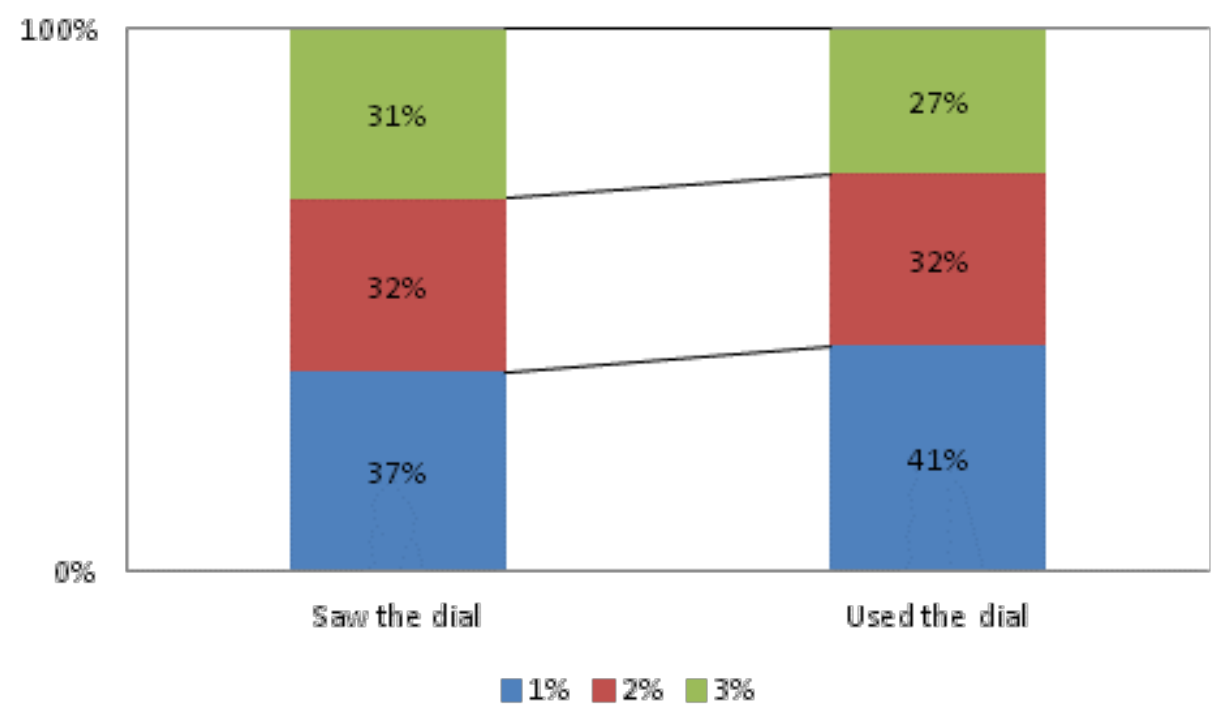

B. Summary of anchor usage and voluntary increases

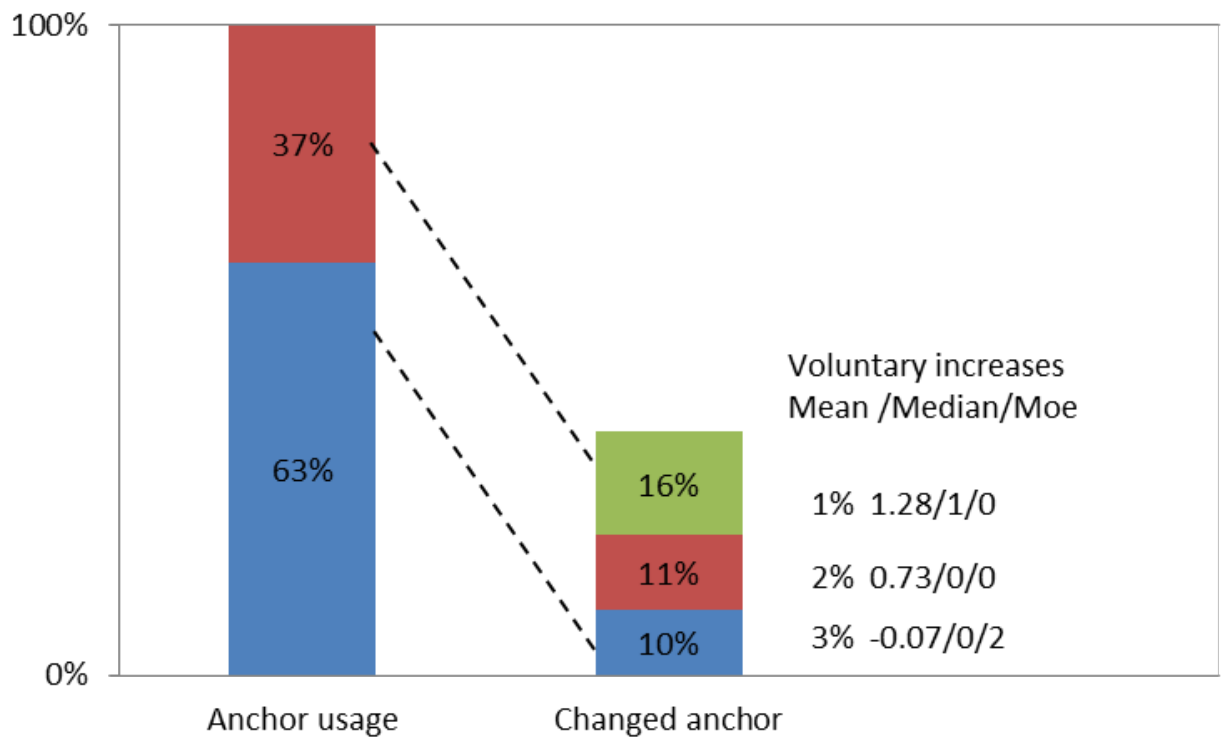

Source: Authors’ tabulations. 